\title{
Information Exchange Article Job Type and Recruiters' Inferences of Applicant Personality Drawn from Resume Biodata: Their Relationships with Hiring Recommendations
}

\author{
Michael S. Cole \\ University of St Gallen
}

\author{
Hubert S. Feild, William F. Giles \\ and Stanley G. Harris \\ Auburn University
}

\begin{abstract}
Using data collected from 244 recruiters who reviewed resumes and made dispositional inferences and hiring recommendations for 122 entry-level job applicants, we found that type of job opening (Holland's Conventional vs. Enterprising jobs) moderated relationships between recruiter inferences of applicant personality traits and recruiter judgments of applicant employability. Results showed Conscientiousness correlated with employability ratings for Conventional jobs (e.g., accounting) while extraversion was most associated with employability ratings for Enterprising jobs (e.g., marketing).
\end{abstract}

$\mathrm{F}$ rom employers' perspectives, job applicants' resumes represent an initial screen in determining if applicants possess requisite knowledge, skills, abilities, and other characteristics required for employment. Recruiters often focus on factual resume content perceived as relevant to the job, such as educational achievements and reported skills. However, in addition to gathering factual data, recruiters apparently make inferences from resume information regarding subjective applicant attributes, such as personality (Kirkwood \& Ralston, 1999), and use these inferences in determining initial employability (Brown \& Campion, 1994; Dindoff, 1999).

Although the legitimacy of inferring applicant personality from their resumes can be debated, it is generally accepted that recruiters frequently form impressions from resume data that go well beyond the education, work experience, and activity information reported on applicants' resumes (Cable \& Gilovich, 1998). However, beyond Dunn, Mount, Barrick, and Ones' (1995) study that reported managers' perceptions of hypothetical applicants' personality traits as important constructs in evaluating their employability, we are not aware of any

Address for correspondence: Michael S. Cole, Institute for Leadership and Human Resource Management, University of St Gallen, Dufourstrasse 40a, CH-9000 St Gallen, Switzerland. E-mail: Michael. Cole@unisg.ch studies that have assessed the relationship between recruiters' inferences of applicant personality traits with their assessments of applicants' employability. For this reason, we sought to determine if experienced recruiters' inferences of job applicants' personality, based solely on their review of actual applicants' resumes, were associated with pre-hire screening decisions. Results from this field research should contribute to understanding of how recruiters' impressions from resumes influence invitations for future applicant assessments such as employment interviews or testing.

For the current study, we propose that recruiters' inferences of applicants' conscientiousness and extraversion will relate to recruiters' employability judgments for entry-level positions sought by recent business school graduates. Although there are other Big 5 personality dimensions, we focus on conscientiousness and extraversion for two reasons. First, conscientiousness has demonstrated a consistent relationship with job performance in most jobs (Salgado, 1997), and extraversion has an established linkage with job performance for jobs involving significant interpersonal interaction (Mount, Barrick, \& Stewart, 1998). Second, studies have linked Big 5 personality traits to Holland's (1996) RIASEC typology of vocational personalities and preferences (Judge, Higgins, Thorensen, \& Barrick, 1999). Organized into one of six occupational personality types: Realistic (R), Investigative 
(I), Artistic (A), Social (S), Enterprising (E), and Conventional (C), research has shown Conventional types received the highest mean score (80th percentile) for conscientiousness (Hogan \& Hogan, 1993), whereas extraversion was positively associated with Enterprising types (Tokar \& Swanson, 1995).

Many business students' vocational interests fall into one of these RIASEC profiles. Conventional types are conforming, methodical, persistent, and conscientious. They prefer occupations that enable them to work with things, numbers, or machines to meet organizational demands or specified standards and see themselves as having technical skills needed for business. Of the Big 5 dimensions, conscientious individuals are purposeful, meticulous, determined, efficient, reliable, and exert selfcontrol in the process of carrying out job responsibilities. For Conventional job-type openings (e.g., accounting), we believe conscientious applicants would be particularly attractive to recruiters.

Enterprising individuals are agreeable, energetic, extraverted, and gregarious. They prefer activities and occupations involving manipulating, directing, or leading others to attain organizational goals and see themselves as possessing persuasion and sales abilities (Holland, 1996). Extraverted individuals are likely to be more comfortable with the social interaction needed to perform successfully in Enterprising jobs. For Enterprising job types, including management and sales positions, being energetic, sociable, assertive, ambitious, and working well with others are expected to contribute to job success. Therefore, applicants perceived by recruiters as being extraverted are expected to receive higher employability judgments for Enterprising jobs. Thus, we hypothesize that job type (i.e., Conventional vs. Enterprising) will moderate the relationship between recruiters' inferences of applicant personality drawn from resume information and recruiters' ratings of applicant employability. Specifically, we predict that applicants thought to be high in conscientiousness will receive higher hiring recommendations for Conventional job types (i.e., accounting, finance, management information systems) than applicants inferred to be low in conscientiousness. In addition, applicants who are inferred to be high in extraversion will receive higher hiring recommendations for Enterprising job types (i.e., marketing, human resources management, business administration) than applicants inferred to be low in extraversion.

\section{Method}

\section{Participants}

Job Applicants' Resumes. Resumes were solicited from 172 college of business seniors enrolled in courses at a large university located in the south-eastern United States. All seniors were in their final semester before graduation. We eliminated 56 resumes that were either obviously poorly prepared or reported majors not typically found in colleges of business (e.g., aviation management), resulting in 122 usable applicant resumes. Subsequent tests showed no demographic differences for the retained applicant resumes and those removed from the study.

The applicant sample was $50 \%$ female, $90 \%$ Caucasian, and averaged 22 years of age. Over four out of five $(83 \%)$ indicated they would be seeking full-time employment in the next 6 months, and $71 \%$ reported having previously interviewed for a full-time job. Moreover, $45 \%$ had experienced follow-up interviews, and $43 \%$ had at least one job offer.

Organizational Recruiters. We contacted 5000 recruiters by mail using a mailing list purchased from the Society for Human Resource Management (SHRM). We specifically selected recruiters living in one of five south-eastern states: Alabama, Florida, Georgia, Mississippi, and Tennessee. Given that the resumes being evaluated were from Auburn University, located in Alabama, it was presumed recruiters from the remaining four states would be familiar with the applicants' university. Of those replying, $321(7 \%)$ recruiters volunteered to participate. Although this is a low response rate, the rate, in part, is because of requirements mandated by the database owner, SHRM. SHRM required that we could only send an officially approved solicitation letter to SHRM members; no initial mailing of a questionnaire was permitted. Only then could we mail recruiters a packet containing a description of the study, one applicant resume, an applicant-rating booklet and questionnaire, and a self-addressed, stamped return envelope. Overall, our return rate was not considerably lower than that of other studies utilizing the SHRM database (cf., $14 \%$; Rynes \& Rosen, 1995).

We mailed research packets to 244 recruiters (two recruiters for each of the 122 applicant resumes). However, 54 withdrew, and we replaced them with randomly selected recruiters who had previously volunteered. The final sample of 244 resume reviewers consisted of human resource professionals specializing in recruitment and representing a variety of organizations including services $(48 \%)$, manufacturing $(19 \%)$, government or nonprofit $(16 \%)$, and other $(18 \%)$. Over $60 \%$ were employed by organizations with 1000 or more employees. They were primarily female $(68 \%)$ and averaged 39 years of age. Most $(92 \%)$ were college graduates, with $40 \%$ reporting an advanced degree. Over half $(53 \%)$ spent $25 \%$ or more of their time reviewing applicants' resumes.

\section{Job Applicant Measures}

RIASEC Academic Major Classifications. We independently categorized applicants' academic majors into Holland's (1996) RIASEC profiles. With unanimous agreement between two coauthors, academic majors in accounting, finance, and management information systems were classified as Conventional type $(n=66)$, and 
academic majors in marketing, human resource management, and business administration were classified as Enterprising type $(n=56)$.

As a check to see if recruiters actually considered relevant jobs for academic majors listed on the applicants' resumes, we examined recruiters' qualitative responses to an open-ended item included on the recruiter questionnaire. The item asked recruiters to list the job title of which they were thinking when they made their applicant employability ratings. Overall, $98 \%$ of recruiters listed a job title. For resumes having majors we classified as Conventional, the recruiters appeared to have considered relevant jobs suitable for applicants' majors. For example, $89 \%$ of recruiters receiving applicant resumes that indicated an accounting major said they were thinking of "accountant" or "entry-level accounting" positions. For finance applicants, $90 \%$ listed positions of "finance" or "financial analyst," and for management information systems majors, $98 \%$ indicated "information systems" or a closely related title. Similar results were found for majors classified as Enterprising. Therefore, we concluded recruiters apparently used academic major and career objectives information given on the resumes when reviewing applicants for relevant jobs.

\section{Resume-Recruiter Measures}

Position-Hiring Scenario. In order to provide a common job referent for recruiters making resume judgments, we developed a hypothetical, position-hiring scenario. Recruiters were told to "Assume that in your organization, there are open, entry-level positions suitable for recent graduates from schools and colleges of business. Such positions are open in each department or functional area of your organization, that is, accounting, human resources, marketing, information systems, etc. Now, read the resume enclosed with this Resume Rating Booklet. Consider that you have just received this resume from a new college graduate who is applying for one of your open positions that fits his/her major field of study as indicated on his/her resume." Following the hiring scenario in the Resume Rating Booklet were specific questions regarding the job applicant.

Applicant Personality Measures. Recruiters assessed applicants' personality using adjective trait rating scales developed in a prior study and patterned after Goldberg (1992). After reading the resume, they rated the extent to which they believed each adjective accurately described the applicant. Recruiters assessed applicants on each of the Big 5 personality domains; however, we were only interested in two of these domains in the present study. The two personality domains, adjectives composing the rating scales, and scale coefficient $\alpha$ 's were: (a) extraversion $=$ enthusiastic, sociable, energetic, extraverted, and active $(\alpha=.90)$ and (b) conscientiousness $=$ hardworking, organized, thorough, responsible, and systematic $(\alpha=.88)$.
Hiring Recommendation. Recruiters assessed applicants' employability using a four-item scale (Cable \& Judge, 1997). Two items asked recruiters to indicate the likelihood that they would (a) be interested in interviewing the applicant and (b) recommend the applicant be hired. Recruiters were also asked, "If hired for the hypothetical position, how likely is it that this applicant would succeed in the job?" The final item asked recruiters, "Taking everything into consideration regarding the applicant's resume, what is your overall evaluation of the candidate?" When subjected to an exploratory factor analysis, the four items loaded on a single factor that explained $86 \%$ of the variance; $\alpha=.94$. Because of differences among item-rating anchors, we standardized responses before computing scale scores.

Recruiter Control Variables. Because previous research reported that recruiters' personal characteristics were associated with their selection decisions, we used the following recruiter characteristics as control variables: gender, experience in evaluating resumes, job title, industry type, and organization size.

Resume Content Control Variables. We also controlled for recruiters' perceptions of resume content in our analyses. Inclusion of resume content information as controls was important for two reasons. First, recruiters not only devalue missing information and prefer candidates with complete information but also weight negative information too heavily and positive information too lightly. Second, recruiters' inferences and employability ratings were based on applicants' self-reported resume content. Therefore, it was important to control for resume items associated with recruiters' initial screening decisions.

To assess recruiters' ratings of resume content, we measured resume content using a scheme developed by Brown and Campion (1994). Recruiters judged the extent to which a variety of items were reported on applicants' resumes. A confirmatory factor analysis of recruiters' ratings of the presence of these items confirmed three content categories. Education (seven items; $\alpha=.68$ ) consisted of resume items such as, GPA in major, earned \% of college expenses, and Dean's list membership. Work Experience (three items; $\alpha=.58$ ) involved the resume items, full-time work experience, supervision of others, and individual job achievements. Activities/Honors (five items; $\alpha=.76$ ) represented resume items, such as membership in professional societies and membership in college clubs. These three factors closely paralleled the three general categories of applicant information typically found on resumes (Brown \& Campion, 1994). Scale scores used in subsequent analyses for each of the three factors were computed by averaging their respective item ratings.

\section{Results}

All interaction terms in the moderated regression analysis (see Table 1) were grand mean centered (Aiken \& West, 
Table 1. Hierarchical moderated regression results for recruiters' inferences of personality from applicant resumes and estimates of applicant employability

\begin{tabular}{|c|c|c|}
\hline \multirow[b]{2}{*}{ Variable } & \multicolumn{2}{|c|}{$\begin{array}{c}\text { Applicant } \\
\text { employability }\end{array}$} \\
\hline & $\Delta R^{2}$ & $\beta$ \\
\hline \multicolumn{3}{|l|}{ Step 1: Recruiter controls } \\
\hline Gender & & .02 \\
\hline Experience & & -.01 \\
\hline Job title & & -.01 \\
\hline Organization size & & -.05 \\
\hline Industry type & & -.04 \\
\hline$\Delta R^{2}$ after Step 1 & .04 & \\
\hline \multicolumn{3}{|l|}{ Step 2: Resume content controls } \\
\hline Education & & .07 \\
\hline Work experience & & $.11^{\star}$ \\
\hline Activities/honors & & $.21 * *$ \\
\hline$\Delta R^{2}$ after Step 2 & $.17^{* *}$ & \\
\hline \multicolumn{3}{|l|}{ Step 3: Main effects } \\
\hline Conscientiousness & & $.37 * *$ \\
\hline Extraversion & & $.16^{*}$ \\
\hline RIASEC job opening ${ }^{1}$ & & $-.16^{\star}$ \\
\hline$\Delta R^{2}$ after Step 3 & $.20 * *$ & \\
\hline \multicolumn{3}{|l|}{ Step 4: Two-way interactions } \\
\hline $\begin{array}{l}\text { Conscientiousness } \times \text { RIASEC } \\
\text { job opening }\end{array}$ & & $-.15^{*}$ \\
\hline $\begin{array}{l}\text { Extraversion } \times \text { RIASEC } \\
\text { job opening }\end{array}$ & & $.13^{*}$ \\
\hline$\Delta R^{2}$ after Step 4 & $.02 *$ & \\
\hline$R^{2}$ & & $.42^{* *}$ \\
\hline Adjusted $R^{2}$ & & .39 \\
\hline
\end{tabular}

Note: $N=230 .{ }^{1}$ RIASEC job opening codes based on Holland's typology ( $1=$ Conventional; 2 = Enterprising). ${ }^{*} p<.05$ (two-tail), ${ }^{* *} p<.01$ (two-tail).

1991). Hypothesis 1 predicted that applicants inferred to be high in conscientiousness will receive higher employability ratings for Conventional job openings than applicants inferred to be low in conscientiousness. The two-way interactions in step four explained unique variance $\left(\Delta R^{2}=.02, p<.05\right)$, and the standardized $\beta$ weight for conscientiousness $\times$ RIASEC job opening was significant $(\beta=-.15, p<.05)$. Furthermore, as shown by the plot of the interaction in Figure 1, applicants who were judged from their resume information to have high conscientiousness levels and who were interested in Conventional job openings (e.g., accounting, finance) received higher overall employability judgments than high-conscientious applicants interested in Enterprising jobs (e.g., marketing, human resources management). Recruiters who perceived applicants as being low conscientious individuals tended to

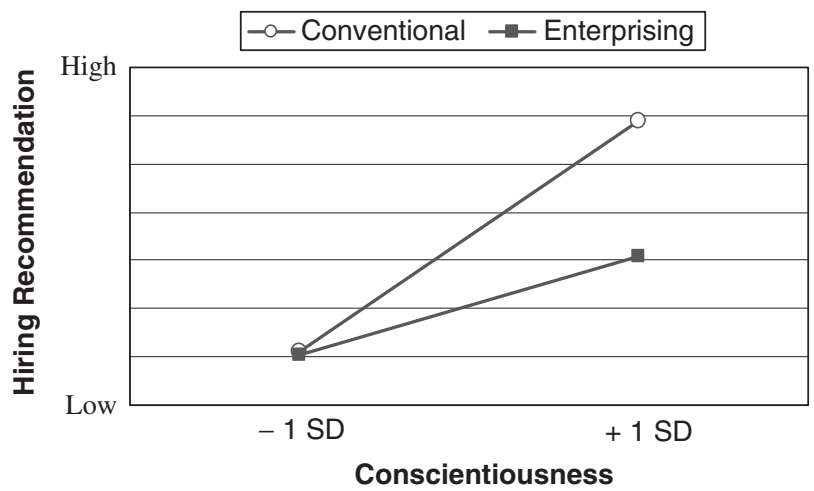

Figure 1. Plot of perceived applicant conscientiousness $\times$ RIASEC job-type interaction on applicant employability. RIASEC, Realistic (R), Investigative (I), Artistic (A), Social (S), Enterprising (E), and Conventional (C).

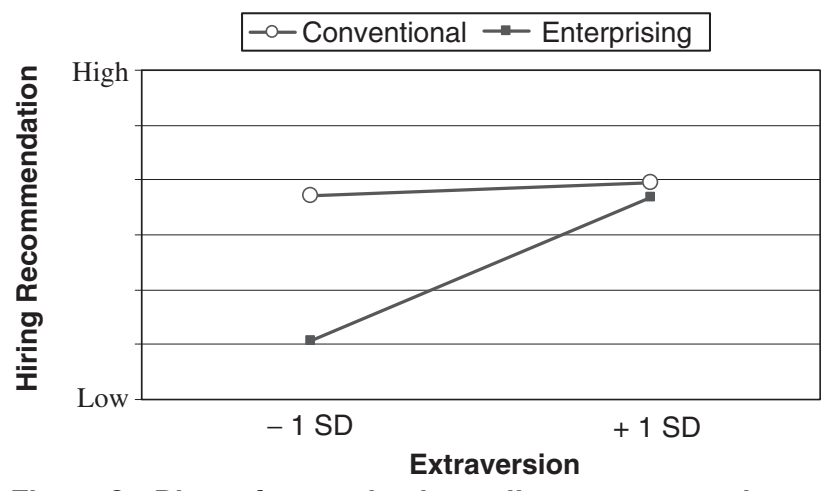

Figure 2. Plot of perceived applicant extraversion $x$ RIASEC job-type interaction on applicant employability. RIASEC, Realistic (R), Investigative (I), Artistic (A), Social $(S)$, Enterprising (E), and Conventional (C).

give low employability ratings regardless of the type of position opening.

In Hypothesis 2, we predicted that applicants judged to be high in extraversion will receive higher employability ratings for Enterprising job openings than will applicants perceived to be low in extraversion. The two-way interaction in step four of the hierarchical moderated regression was significant (see Table 1). In turn, the standardized $\beta$ weight for perceived applicant extraversion $\times$ RIASEC job opening interaction was associated with applicant employability $(\beta=.13, p<.05)$. A plot of the interaction in Figure 2 shows that applicants perceived as high in extraversion and who were interested in Enterprising jobs received higher overall employability judgments than applicants inferred by recruiters as being low in extraversion.

\section{Discussion}

Despite the universality of resume screening and the resources devoted to it in pre-screening decisions, many have noted there is surprisingly little empirical research examining the inferences drawn by recruiters and their use of resume information when evaluating applicants' employability (Bright \& Hutton, 2000; Brown \& 
Campion, 1994; Dindoff, 1999; Harvey-Cook \& Taffler, 2000). Thus, the present study addresses such calls and extends prior research by examining recruiters' perceptions of applicants' personality as inferred from their resumes as predictors of recruiter hiring recommendations. Type of job opening (Conventional vs. Enterprising) moderated the relationships between recruiter inferences of applicant personality traits and recruiter judgments of applicant employability such that applicants perceived to be low in conscientiousness received low employability ratings regardless of job type. Furthermore, conscientiousness emerged as important for employability in Conventional jobs that required the manipulation of numbers and attention to detail (e.g., accounting and finance) while extraversion was most associated with employability ratings for Enterprising jobs where interpersonal skills are highly valued (e.g., marketing and human resources). These results imply that recruiters, when forming initial impressions regarding employability, apparently not only took into account content of the job being filled but also inferred personality traits that would aid applicants in performing specific types of jobs. These attributions apparently played a role in recruiters' forming hiring recommendations.

In conclusion, current thinking regarding personorganization $(\mathrm{P}-\mathrm{O})$ fit suggests it is important to select applicants with personalities and values that are congruent with those of the organization (Saks \& Ashforth, 2001). Given that recruiters are organizational gatekeepers, the validity of recruiters' inferences regarding applicants' personality needs to be examined. For instance, future research might ask recruiters to assess applicants' personality based on resume content and then correlate recruiters' attributions with applicants' personality based on selfreport inventories. Future research should also determine if structuring the resume evaluation process (e.g., employing a structured resume rating form and training recruiters in how to evaluate applicants' resumes) has any effect on the reliability and validity of recruiters' inference making. If future resume research identifies valid, consistent ties between resume information and applicant personality, resume evaluation's greatest contribution may be as a prescreening tool to aid in assessing applicants' $\mathrm{P}-\mathrm{O}$ fit.

\section{References}

Aiken, L.S. and West, S.G. (1991) Multiple regression: Testing and interpreting interactions. Newbury Park, CA: Sage.
Bright, J.E.H. and Hutton, S. (2000) The impact of competency statements on resumes for short-listing decisions. International Journal of Selection and Assessment, 8, 41-53.

Brown, B.K. and Campion, M.A. (1994) Biodata phenomenology: Recruiters' perceptions and use of biographical information in resume screening. Journal of Applied Psychology, 79, 897-908.

Cable, D.M. and Gilovich, T. (1998) Looked over or overlooked? Prescreening decisions and postinterview evaluations. Journal of Applied Psychology, 83, 501-508.

Cable, D.M. and Judge, T.A. (1997) Interviewers' perceptions of person-organization fit and organizational selection decisions. Journal of Applied Psychology, 82, 546-561.

Dindoff, K.M. (1999). Recruiter impressions of potential for jobspecific and organizational fit in resume screening: Three field studies. Unpublished dissertation. University of Western Ontario, London, Ontario.

Dunn, W.S., Mount, M.K., Barrick, M.R. and Ones, D.S. (1995) Relative importance of personality and general mental ability in managers' judgments of applicant qualifications. Journal of Applied Psychology, 80, 500-509.

Goldberg, L.R. (1992) The development of markers for the Big Five factor structure. Psychological Assessment, 4, 26-42.

Harvey-Cook, J.E. and Taffler, R.J. (2000) Biodata in professional entry-level selection: Statistical scoring of common format applications. Journal of Occupational and Organizational Psychology, 73, 103-118.

Hogan, J. and Hogan, R.T. (1993, May) The ambiguity of conscientiousness. In F.L. Schmidt (Chair), The construct of "conscientiousness" in personnel selection. Symposium presented at the Society for Industrial and Organizational Psychology Meeting, San Francisco.

Holland, J.L. (1996) Exploring careers with a typology: What we have learned and some new directions. American Psychologist, 51, 397-406.

Judge, T.A., Higgins, C.A., Thoresen, C.J. and Barrick, M.R. (1999) The Big Five personality traits, general mental ability, and career success across the life span. Personnel Psychology, 52, 621-652.

Kirkwood, W.G. and Ralston, S.M. (1999) Inviting meaningful applicant performances in employment interviews. The Journal of Business Communication, 36, 55-76.

Mount, M.K., Barrick, M.R. and Stewart, G.L. (1998) FiveFactor Model of personality and performance in jobs involving interpersonal interactions. Human Performance, 11, $145-165$.

Rynes, S.L. and Rosen, B. (1995) A field study of factors affecting the adoption and perceived success of diversity training. Personnel Psychology, 48, 247-270.

Saks, A.M. and Ashforth, B.E. (2001) Is job search related to employment quality? It all depends on the fit. Journal of Applied Psychology, 87, 646-654.

Salgado, J.F. (1997) The five factor model of personality and job performance in the European Community. Journal of Applied Psychology, 82, 30-43.

Tokar, D.M. and Swanson, J.L. (1995) Evaluation of the correspondence between Holland's vocational personality typology and the five-factor model of personality. Journal of Vocational Behavior, 46, 89-108. 